\title{
High Resolution Melt (HRM) analysis is an efficient tool to genotype EMS mutants in complex crop genomes
}

Seosamh Ó Lochlainn ${ }^{1 \dagger}$, Stephen Amoah ${ }^{2 \dagger}$, Neil S Graham ${ }^{1 \dagger}$, Khalid Alamer ${ }^{1}$, Juan J Rios ${ }^{1}$, Smita Kurup², Andrew Stoute ${ }^{2}$, John P Hammond ${ }^{1}$, Lars Østergaard ${ }^{3}$, Graham J King ${ }^{4}$, Phillip J White ${ }^{5}$ and Martin R Broadley ${ }^{1 *}$

\begin{abstract}
Background: Targeted Induced Loci Lesions IN Genomes (TILLING) is increasingly being used to generate and identify mutations in target genes of crop genomes. TILLING populations of several thousand lines have been generated in a number of crop species including Brassica rapa. Genetic analysis of mutants identified by TILLING requires an efficient, high-throughput and cost effective genotyping method to track the mutations through numerous generations. High resolution melt (HRM) analysis has been used in a number of systems to identify single nucleotide polymorphisms (SNPs) and insertion/deletions (IN/DELs) enabling the genotyping of different types of samples. HRM is ideally suited to high-throughput genotyping of multiple TILLING mutants in complex crop genomes. To date it has been used to identify mutants and genotype single mutations. The aim of this study was to determine if HRM can facilitate downstream analysis of multiple mutant lines identified by TILLING in order to characterise allelic series of EMS induced mutations in target genes across a number of generations in complex crop genomes.
\end{abstract}

Results: We demonstrate that HRM can be used to genotype allelic series of mutations in two genes, BraA.CAX1a and BraA.MET1.a in Brassica rapa. We analysed 12 mutations in BraA.CAX1.a and five in BraA.MET1.a over two generations including a back-cross to the wild-type. Using a commercially available HRM kit and the Lightscanner ${ }^{\mathrm{TM}}$ system we were able to detect mutations in heterozygous and homozygous states for both genes.

Conclusions: Using HRM genotyping on TILLING derived mutants, it is possible to generate an allelic series of mutations within multiple target genes rapidly. Lines suitable for phenotypic analysis can be isolated approximately 8-9 months (3 generations) from receiving $M_{3}$ seed of Brassica rapa from the RevGenUK TILLING service.

Keywords: TILLING, HRM, Brassica, genotyping

\section{Background}

The identification and analysis of gene mutations in plants is fundamental to the investigation of gene function. One approach, Targeted Induced Loci Lesions IN Genomes (TILLING) was originally developed in Arabidopsis [1] and has subsequently been successful in a range of crop plants [2,3]. In this reverse genetic approach, an ethyl methane sulfonate (EMS) mutagenised population is screened for SNPs within target genes

\footnotetext{
* Correspondence: martin.broadley@nottingham.ac.uk

+ Contributed equally

'School of Biosciences, University of Nottingham, Sutton Bonington Campus, Loughborough LE12 5RD, UK

Full list of author information is available at the end of the article
}

[4]. EMS mutagenesis generates multiple alleles within each gene, including nonsense, missense, splicing and cis-regulatory mutants, in comparison to T-DNA and transposon mutagenesis that generate only knockout mutants [5,6]. Analysis of an allelic series can provide information on important domains or amino acids within the protein of interest. A number of TILLING populations have been developed for a variety of crops of different genome size, including rice [2], wheat $[7,8]$, Brassica rapa [3], Brassica napus [9], Lotus japonicus [10], Medicago trunculata [11], Arachis hypogaea [12], and Solanum lycopersicum [13]. These populations have subsequently been used to isolate mutations in a variety

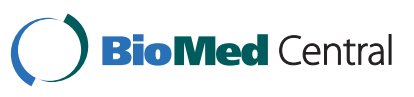


of genes, including those involved in starch metabolism in Lotus japonicas [14], peanut allergens [12] and a gene encoding a fatty acid elongase [9].

High resolution melt (HRM) analysis is a technique that measures the disassociation of double-stranded DNA at high temperature resolution, and permits the analysis of genetic variations (SNPs, mutations, methylation) in PCR amplicons [15-17]. This technique allows genotyping and mutation scanning without the need for costly labeled probes, as it uses high fidelity heteroduplex-detecting double-stranded DNA binding dyes, such as EvaGreen which exhibit equal binding affinities for GC-rich and AT-rich regions and no sequence preference $[18,19]$. The heteroduplex products are detected by the presence of a second low-temperature melting transition [20]. This enables the reaction to be performed in a single tube, making it cost-effective and suitable for high-throughput screening [17]. HRM has been used extensively in the genotyping of human tissue samples for the identification of genes associated with diseases $[21,22]$ as well as identification of clinically important fungal species [23]. HRM has been used for quantitative detection of adulteration with related species of pants used for medicinal purposes [24]. HRM has been used previously to identify mutations in TILLING populations of tomato [13], wheat [8] and Medaka [25]. In the tomato study, HRM was used to identify mutations using DNA pools from an EMS mutagenised population of plants. The wheat studies demonstrated that HRM can be used to isolate novel mutations in starch branching enzyme IIa (SBEIIa) genes from an EMS population [8] and in mutation scans in mixed PCR amplicons containing three homeologous gene fragments [19]. It was also demonstrated that homozygous and heterozygous individuals of a single mutation could be genotyped using HRM [19].

The genus Brassica includes the closest crop relatives of Arabidopsis thaliana, such as B. rapa (A-genome, $2 \mathrm{n}$ $=2 \mathrm{x}=20, \sim 550 \mathrm{Mbp}$ ), which includes vegetable crops (e.g. turnip, Chinese cabbage) and oil-seed crops, $B$. oleracea (C-genome, $2 \mathrm{n}=2 \mathrm{x}=18,>600 \mathrm{Mbp}$ ) which includes vegetable crops (cauliflower, broccoli, cabbage) and the amphidiploid B. napus (AC-genome, $2 \mathrm{n}=4 \mathrm{x}=$ 38, $1100 \mathrm{Mbp}$ ), which includes oil-seed crops (canola, oilseed rape) and swede. As with many crop plants Brassica genomes are complex arising from a series of duplication events that has resulted in most genes being present in multiple paralogous and homeologous copies $[26,27]$. A TILLING population has recently been generated in $B$. rapa to enable gene function to be analysed [3] and has previously been used to identify mutations in the Brapa orthologue of the INDEHISCENT gene [28]. The aim of this study is to determine if HRM analysis can be used to genotype TILLING mutants in the crop species $B$. rapa and thereby to improve the efficiency of functional genomics approaches in this species.

\section{Results and Discussion \\ Gene selection and TILLING}

In order to demonstrate that HRM is suitable for efficient genotyping of mutant lines identified using TILLING, two target genes were chosen, BraA.CAX1.a and BraA.MET1.a. In A. thaliana, CAX1 has been shown to encode a calcium-proton antiporter [29] and MET1 has been shown to encode a DNA methyltransferase [30]. The CAX1 sequence from A. thaliana [Genbank: NM_129373.3] was used to identify the homologous sequence from $B$. rapa and from this sequence, $1.5 \mathrm{~kb}$ including the transcriptional start was used as the target for TILLING. To isolate BraA.MET1.a from B. rapa Ro-18, primers were designed based on the $B$. rapa Chiifu-401 sequence [Genbank:AB251937] [31]. These produced a 2110 bp DNA fragment covering $136 \mathrm{bp}$ upstream of the translational start site together with the first intron and the first $407 \mathrm{bp}$ of the second exon. Both sequences were submitted to the RevGenUK TILLING service, which resulted in 20 and 17 mutations being identified in BraA.CAX1.a and BraA.MET1.a respectively (Table 1 ). These mutations included silent, missense, nonsense and non-coding mutations.

\section{Genotyping of TILLING lines using HRM}

From the lines identified using TILLING, twelve (BraA.cax1.a-1, -4, -6, -7, -8, -10,-11, -12, -14,-16, $-18,-20)$ and five (BraA.met1.a-3, -6, -7, -10 and -14 ) lines carrying mutations in BraA.CAX1 and BraA. MET1.a respectively were chosen to be characterised based on the nature and position of the mutation. In order to genotype the lines, a HRM assay was developed for each gene. To increase the specificity of the HRM reaction a nested PCR approach was used for the BraA.cax1.a lines, first using the TILLING primers to amplify genomic DNA, prior to using the HRM primers with this product. In total, three primer pairs were designed to genotype all 12 mutations within the BraA.CAX1.a gene (amplifying fragments of 200, 203 and $260 \mathrm{bp}$; Table 2) and one primer pair was designed to genotype all the mutations within the BraA.MET1.a gene (amplifying a 399 bp fragment; Table 2). Individual $M_{3}$ plants of the TILLING lines and wild-type Ro-18 plants were then genotyped using the HRM assay using a single primer pair per plate and three technical replicates per plant, allowing multiple alleles to be genotyped in a single scanning run. Analysis of the difference plots for the fluorescent signals detected individual plants that were wild-type, homozygous or heterozygous for the mutation in alleles of both genes (Figure 1). Three distinct groups can readily be 
Table 1 Nucleotide changes in BraA.cax1.a and BraA.met1.a TILLING mutants.

\begin{tabular}{|c|c|c|c|c|}
\hline Line $^{a}$ & Mutation Change $^{\mathrm{b}}$ & Position (base-pair) $^{c}$ & Position (amino-acid) $^{d}$ & Type of mutation ${ }^{e}$ \\
\hline BraA.cax1.a-1 & $\mathrm{G}$ to $\mathrm{A}$ & 881 & - & Non-coding \\
\hline BraA.cax1.a-2 & $\mathrm{C}$ to $\mathrm{T}$ & 860 & - & Non-coding \\
\hline BraA.cax1.a-3 & $\mathrm{G}$ to $\mathrm{A}$ & 545 & 2 & Non-coding \\
\hline BraA.cax1.a-4 & $\mathrm{G}$ to $\mathrm{A}$ & 771 & 77 & Missense \\
\hline BraA.cax1.a-5 & $\mathrm{C}$ to $\mathrm{T}$ & 494 & - & Non-coding \\
\hline BraA.cax1.a-6 & $\mathrm{G}$ to $\mathrm{A}$ & 517 & - & Non-coding \\
\hline BraA.cax1.a-7 & $\mathrm{G}$ to $\mathrm{A}$ & 673 & 44 & Missense \\
\hline BraA.cax1.a-8 & $\mathrm{G}$ to $\mathrm{A}$ & 599 & 19 & Missense \\
\hline BraA.cax1.a-9 & $\mathrm{G}$ to $\mathrm{A}$ & 645 & 35 & Missense \\
\hline BraA.cax1.a-10 & $\mathrm{C}$ to $\mathrm{T}$ & 736 & 65 & Missense \\
\hline BraA.cax1.a-11 & $\mathrm{G}$ to $\mathrm{A}$ & 795 & 85 & Missense \\
\hline BraA.cax1.a-12 & $\mathrm{C}$ to $\mathrm{T}$ & 708 & 56 & Missense \\
\hline BraA.cax1.a-13 & $\mathrm{C}$ to $\mathrm{T}$ & 689 & 49 & Silent \\
\hline BraA.cax1.a-14 & $\mathrm{C}$ to $\mathrm{T}$ & 661 & 40 & Missense \\
\hline BraA.cax1.a-15 & $C$ to $T$ & 658 & 39 & Missense \\
\hline BraA.cax1.a-16 & $\mathrm{C}$ to $\mathrm{T}$ & 421 & - & Non-coding \\
\hline BraA.cax1.a-17 & $\mathrm{G}$ to $\mathrm{A}$ & 926 & - & Non-coding \\
\hline BraA.cax1.a-18 & $\mathrm{C}$ to $\mathrm{T}$ & 818 & 92 & Silent \\
\hline BraA.cax1.a-19 & $\mathrm{C}$ to $\mathrm{T}$ & 732 & 64 & Missense \\
\hline BraA.cax1.a-20 & $\mathrm{C}$ to $\mathrm{T}$ & 690 & 50 & Nonsense \\
\hline BraA.met1.a-1 & $C$ to $T$ & 3516 & 248 & Silent \\
\hline BraA.met1.a-2 & $\mathrm{G}$ to $\mathrm{A}$ & 3334 & 188 & Missense \\
\hline BraA.met1.a-3 & $\mathrm{G}$ to $\mathrm{A}$ & 3334 & 188 & Missense \\
\hline BraA.met1.a-4 & $\mathrm{G}$ to $\mathrm{A}$ & 3084 & 104 & Silent \\
\hline BraA.met1.a-5 & $\mathrm{C}$ to $\mathrm{T}$ & 3081 & 103 & Silent \\
\hline BraA.met1.a-6 & $\mathrm{G}$ to $\mathrm{A}$ & 3252 & 243 & Nonsense \\
\hline BraA.met1.a-7 & $\mathrm{G}$ to $\mathrm{A}$ & 3500 & 243 & Missense \\
\hline BraA.met1.a-8 & $\mathrm{G}$ to $\mathrm{A}$ & 3012 & 80 & Silent \\
\hline BraA.met1.a-9 & $\mathrm{G}$ to $\mathrm{A}$ & 3495 & 241 & Silent \\
\hline BraA.met1.a-10 & $\mathrm{C}$ to $\mathrm{T}$ & 3335 & 188 & Missense \\
\hline BraA.met1.a-11 & $C$ to $T$ & 3069 & 99 & Silent \\
\hline BraA.met1.a-12 & $\mathrm{G}$ to $\mathrm{A}$ & 3330 & 186 & Silent \\
\hline BraA.met1.a-13 & $C$ to $T$ & 3324 & 184 & Silent \\
\hline BraA.met1.a-14 & $\mathrm{G}$ to $\mathrm{A}$ & 3213 & 147 & Nonsense \\
\hline BraA.met1.a-15 & $\mathrm{C}$ to $\mathrm{T}$ & 3265 & 165 & Silent \\
\hline BraA.met1.a-16 & $\mathrm{G}$ to $\mathrm{A}$ & 3330 & 186 & Silent \\
\hline BraA.met1.a-17 & $\mathrm{G}$ to $\mathrm{A}$ & 3258 & 162 & Silent \\
\hline
\end{tabular}

${ }^{a}$ - TILLING line, ${ }^{b}$ - Nucleotide change in mutant line, ${ }^{c}$ - Position of nucleotide change in base-pairs, ${ }^{d}$ - Position of amino-acid change in peptide, ${ }^{e}$ - Type of mutation caused by nucleotide change. Non-coding - nucleotide change not within coding region, missense - nucleotide change results in an amino-acid change, nonsense - nucleotide change results in the introduction of a premature stop codon, silent - no change in amino-acid.

observed in the difference plots. To confirm these results and assign zygosity groups, the PCR products from selected lines were sequenced. Sequencing the HRM PCR products identified by HRM as heterozygous from BraA.cax1.a-11 and BraA.met1.a-6, showed a double peak at the position of the mutation (Figure 2 ), confirming that these were indeed heterozygous for the mutations. In addition, sequencing of PCR products from BraA.cax1.a-1 and BraA.met1.a-6 identified as homozygous by HRM, confirmed that they were homozygous for the mutation (Figure 2). These results demonstrate that HRM can be used both for rapid genotyping of TILLING mutants and for distinguishing wild-type, heterozygous and homozygous plants. The 
Table 2 Details of primers used for gene isolation and HRM analysis.

\begin{tabular}{|c|c|c|c|c|}
\hline Primer $^{a}$ & Gene $^{b}$ & Stage $^{c}$ & Mutation Targeted $^{d}$ & Sequence $5^{\prime}$ to $3^{\prime e}$ \\
\hline BrCAX1 TILLING_Forward & BraA.CAX1.a & TILLING & & AGAGATTTCCTAGCCATGTG \\
\hline BrCAX1 TILLING_Reverse & BraA.CAX1.a & TILLING & & CGACCCCTAATTGTTTTATGTG \\
\hline BrCAX1 HRM1_Forward & BraA.CAX1.a & HRM & 6,16 & TCCTCGAAGTTGCCTCTGAT \\
\hline BrCAX1 HRM1_Reverse & BraA.CAX1.a & HRM & 6,16 & GCTGCTGACCATTGTTCCTG \\
\hline BrCAX1 HRM3_Forward & BraA.CAX1.a & HRM & $7,8,12,14,20$ & GCAGGAACAATGGTCAGCAG \\
\hline BrCAX1 HRM3_Reverse & BraA.CAX1.a & HRM & $7,8,12,14,20$ & CGAGAATGACTTCTTGGAGATT \\
\hline BrCAX1 HRM6_Forward & BraA.CAX1.a & HRM & $4,10,11,18$ & TCCAGAAGGTTCCATACAAAGG \\
\hline BrCAX1 HRM6_Reverse & BraA.CAX1.a & HRM & $4,10,11,18$ & CGCTGTTCTGTTTAGTAATGTGTTG \\
\hline BrMet1aF4 & BraA.MET1.a & Gene isolation & & ACTTCACAGCATCTCCTCAGGGC \\
\hline BrMet1aF5 & BraA.MET1.a & Gene isolation & & CTTGACAATGGTGCTGTTATTCAG \\
\hline BrMet1aF6 & BraA.MET1.a & Gene isolation & & GTCTGGTTTGATGGCAGAGGACG \\
\hline BrMet1aR4 & BraA.MET1.a & Gene isolation & & CGCACTTCGCAGCTTCAGAAAC \\
\hline BrMet1aR5 & BraA.MET1.a & Gene isolation & & AAATAGAGATTGTTGAACACCCCC \\
\hline BrMet1aR6 & BraA.MET1.a & Gene isolation & & TTGGATACCACAGGTGCCATGC \\
\hline BrMet1aHRMF & BraA.MET1.a & HRM & $3,6,7,10,14$ & TGCGATGATAAGGAGAAAGG \\
\hline BrMet1aHRMR & BraA.MET1.a & HRM & $3,6,7,10,14$ & TTTGCCGTCTCATCCAAAC \\
\hline
\end{tabular}

a- Primer name, ${ }^{b}$-gene primer designed to, ${ }^{c}$-stage of analysis primer used, ${ }^{\mathrm{d}}$-line primers used to genotype, ${ }^{\mathrm{e}}$ - sequence of primer

results also demonstrate that multiple alleles can be genotyped using a single primer pair on one PCR plate, allowing multiple lines and individual plants to be genotyped simultaneously.

\section{Backcross analysis}

To reduce the mutation load, reciprocal crosses of the TILLING lines and wild-type R-o-18 plants were performed with both homozygous and heterozygous mutant
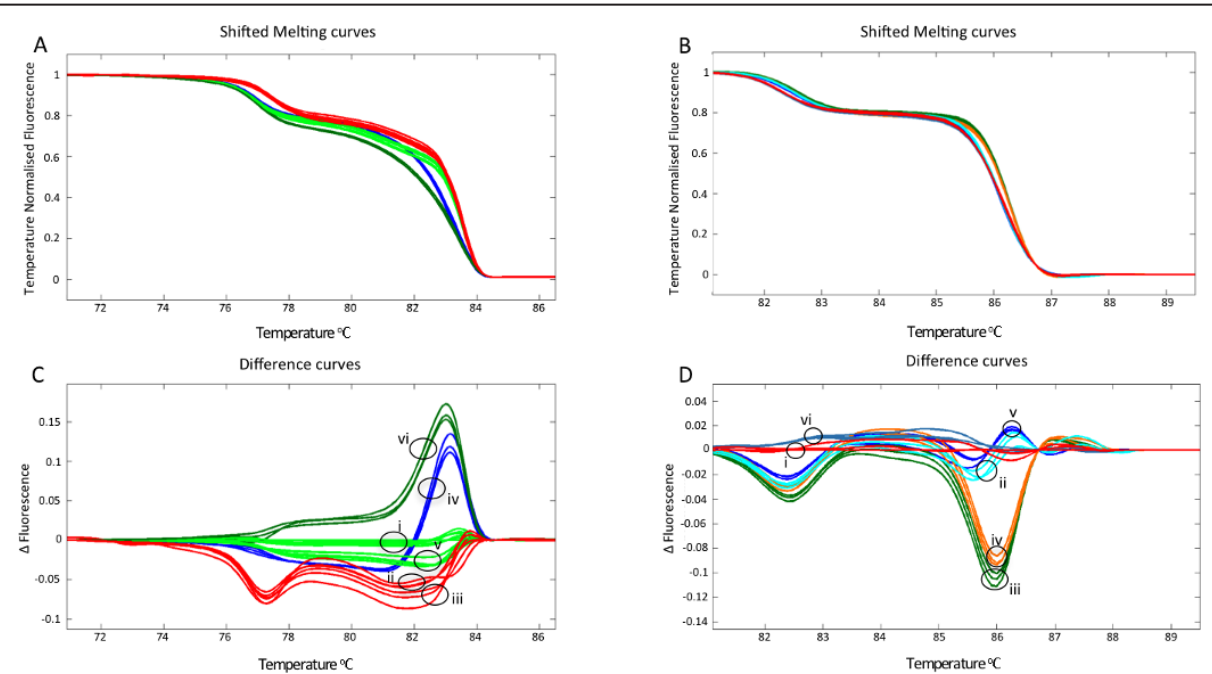

Figure 1 HRM analysis for Brassica rapa R-o-18 wild-type and individual plants from $\mathrm{M}_{3}$ BraA.cax1.a-11 and BraA.met1.a-6 TILLING mutants. A: Normalised melt curves for fluorescent signals from DNA strand dissociation of triplicated technical replicates of $B$. rapa wild-type (light green lines) and individual plants of M3 TILLING mutant BraA.cax1.a-11, plant BraA.cax1.a-11A (red), plant BraA.cax1.a-11B (red), plant BraA. cax1.a-11C (blue), plant BraA.cax1.a-11D (light green), plant BraA.cax1.a-11E (dark green). B: Normalised melt curves for fluorescent signals from DNA strand dissociation of triplicated technical replicates of $B$. rapa wild type (red lines) and individual plants $M_{3}$ TILLING mutant BraA.met1.a-6, plant BraA.met1.a-6-1 (light blue), plant BraA.met1.a-6-2 (green), plant BraA.met1.a-6-3 (orange), plant BraA.met1.a-6-4 (purple), plant BraA.met1.a14-1 (blue). C: Difference plot of genotypes' fluorescence normalised to wild type samples (light green lines, i) and individual plants of $M_{3}$ TILLING mutant BraA.cax1.a-11, plant BraA.cax1.a-11A (red, ii), plant BraA.cax1.a-11B (red, iii), plant BraA.cax1.a-11C (blue, iv), plant BraA.cax1.a-11D (light green, v), plant BraA.cax1.a-11E (dark green, vi). D: Difference plot of genotypes' fluorescence normalised to wild type (red, i) and individual plants of the M3 TILLING mutant BraA.met1.a-2, plant BraA.met1.a-6-1 (light blue, ii), plant BraA.met1.a-6-2 (green, iii), plant BraA.met1.a-6-3 (orange, iv), plant BraA.met1.a-6-4 (purple, v), plant BraA.met1.a-14-1 (blue, vi). 


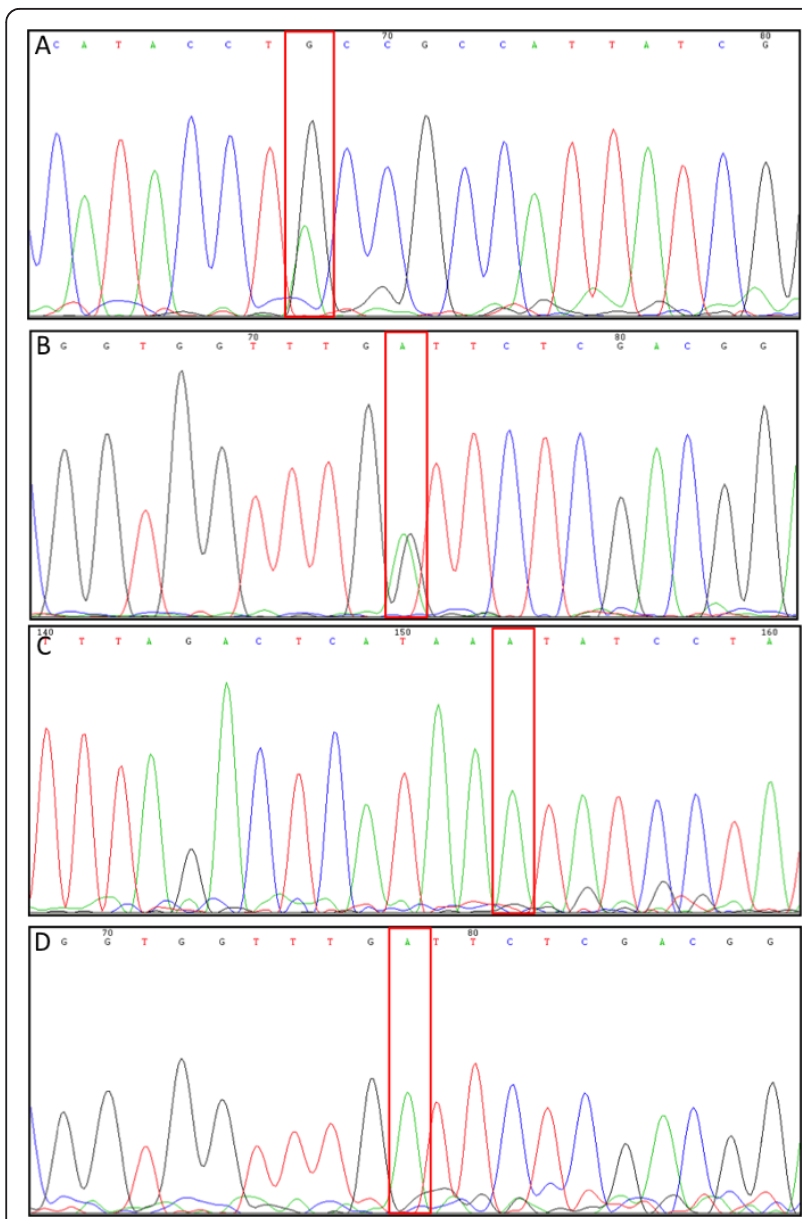

Figure 2 Sequencing chromatograms of $M_{3}$ generation of $B$. rapa R-o-18 mutants. A: BraA.cax1.a-11, gene sequence from 788 bp to 807 bp shown. B: BraA.met1.a-6, gene sequence from 3246 bp to 3265 bp shown. C: BraA.cax1.a-1, gene sequence from 868 bp to 888 bp shown. D: BraA.met1.a-6, gene sequence from 3246 bp to $3265 \mathrm{bp}$ shown. Rectangular box indicates zygosity state at the site of EMS induced transitional mutation.

plants. A heterozygous plant from the BraA.met1.a-6 line was crossed to a wild-type plant and ten $F_{1}$ plants were genotyped. The results from the genotyping showed the expected segregation of the mutant allele, with 5 plants having a heterozygous mutation and 5 plants being wild-type for the mutation. The genotyping results for the $\mathrm{F}_{1}$ plants from crosses of the BraA.cax1.a lines also showed the expected genotyping results (Table 3 ). For example, the $F_{1}$ plants of a cross using a homozygous BraA.cax1.a-1 plant were all heterozygous for the mutation $(n=5)$. In contrast, the $F_{1}$ progeny of heterozygous plants showed segregation for the mutation (Table 3). These results demonstrate that HRM can be used to follow mutations and zygosity through multiple generations and crossing events, making it an ideal method for genotyping of TILLING mutants.

\section{Conclusions}

To analyse an allelic series of mutants generated using the TILLING approach efficiently, a cost effective, highthroughput genotyping technique is required. Techniques that have been used previously include PCR-RFLP, but this relies on the mutation causing a change in a restriction site [32] and TaqMan assays, which can require expensive probes and assay optimisation $[18,33]$. Alternatively, PCR products covering the mutations could be sequenced. However, this is time consuming and potentially more expensive; HRM analysis of samples in triplicate costs $\sim 30 \%$ of Sanger sequencing costs. The results presented here demonstrate that HRM can be used to genotype mutations identified by TILLING from EMS populations in B. rapa. The results also demonstrate that a single PCR primer pair could be used to identify mutations at multiple positions with the PCR fragment. This reduces the number of primer pairs needed to genotype an allelic series and hence the cost. Due to the nature of the HRM process, the DNA extraction, PCRs and melt curve analysis can all be performed in 96-well plates. This enables high-throughput genotyping of multiple alleles of a number of genes to be performed quickly and efficiently. This is particularly important in complex crop species such as $B$ rapa, where paralogous genes may be present and accumulation of mutations may be required to generate a phenotype.

\section{Methods}

\section{Plant material}

Seed of the highly inbred, homozygous, self-compatible, rapid cycling $B$. rapa ssp. trilocularis line $\mathrm{R}-\mathrm{o}-18$ was used as wild-type control. Seeds for lines $\left(\mathrm{M}_{3}\right.$ generation) containing mutations in target genes were obtained from the R-o-18 TILLING population through the RevGenUK service [3,34].

\section{Plant growth conditions}

Plants were grown under glasshouse conditions with a $16 \mathrm{~h}$ photoperiod at $22.3 \pm 4^{\circ} \mathrm{C}$ and $13.3 \pm 2^{\circ} \mathrm{C}$ mean day and night temperatures respectively. Seeds were sown directly into pots (height $11.3 \mathrm{~cm}$; diameter 13 $\mathrm{cm})$ containing Levington M3 high nutrient compost (Monro Group, Chichester, UK) and irrigated twice daily. Following three weeks of vegetative growth, Vitafeed $^{\circledR}$ 2-1-4 nutrient solutions (N-P-K: 16-8-32 + micronutrients; Vitax Ltd., Coalville, Leicestershire, UK) were applied to plants weekly at a rate of $3 \mathrm{~g} \mathrm{l}^{-1}$ via overhead irrigation. Plants initiated flowering after approximately 6 weeks of growth and seeds were collected approximately 4 weeks thereafter. Perforated bread bags (150 $\mathrm{mm} \times 700 \mathrm{~mm}$, WR Wright \& Sons Ltd, Liverpool, UK) 
Table 3 HRM genotyping results of $F_{1}$ progeny of BraA.cax1.a and BraA.met1.a lines crossed to wild-type.

\begin{tabular}{|c|c|c|c|}
\hline Line $^{a}$ & Plant $^{b}$ & Number of heterozygous plants ${ }^{c}$ & Number of wild-type plants ${ }^{d}$ \\
\hline BraA.cax1.a-1 & $E$ & 5 & 0 \\
\hline BraA.cax1.a-4 & C & 2 & 0 \\
\hline BraA.caxi.a-6 & B & 4 & 2 \\
\hline BraA.cax1.a-7 & A & 3 & 3 \\
\hline BraA.cax1.a-8 & A & 4 & 1 \\
\hline BraA.cax1.a-10 & A & 3 & 2 \\
\hline BraA.cax1.a-11 & B & 3 & 3 \\
\hline BraA.cax1.a-12 & A & 3 & 3 \\
\hline BraA.cax1.a-14 & B & 3 & 0 \\
\hline BraA.cax1.a-18 & D & 2 & 4 \\
\hline BraA.cax1.a-20 & A & 2 & 2 \\
\hline BraA.met1.a-6 & A & 5 & 5 \\
\hline
\end{tabular}

were used to enclose inflorescences to prevent crosspollination from neighboring plants.

\section{In silico data mining to identify gene sequences}

Basic Local Alignment Search Tool (BLAST) [35] software was employed to identify sequences from all Brassica spp. that were orthologous to the A. thaliana CAX1 gene [Genbank: NM_129373.3]. All A. thaliana sequences of interest were retrieved from GenBank [36]. For the BLASTn algorithm [37] the entire GenBank database (March 2009) was interrogated to identify all Brassica sequences sharing $>80 \%$ sequence identity at an e-value of $<1 \mathrm{e}^{-30}$ with the A. thaliana query sequence. The Brassica Genome Sequencing Project (BrGSP) database [38] was interrogated (March 2009) using the WuBLAST [39] algorithm for all Brassica BAC-end sequences, fully sequenced BACs, ESTs and genome survey sequence which shared $>80 \%$ sequence identity with this query sequence. A. thaliana genes sharing high sequence similarities to the query gene i.e. members of the same gene family including AtCAX2 [Genbank:NM_001036119.1] and AtCAX3 [Genbank: NM_115045.3] were used to interrogate both databases. After in silico comparative sequence analyses, Brassica sequences were assigned to the member of the A. thaliana gene family with which they shared the highest sequence identity, thus removing false positives. All selected sequences which were orthologous to AtCAX1 were formatted into FASTA and entered into a contig assembly program (ContigExpress, VectorNTI 11, Invitrogen, Paisley, UK) using default settings to form longer contiguous Brassica sequences and identify possible locus specific paralogues. These nascent Brassica gene sequences were aligned to the A. thaliana gene of interest, flanked at either end with $1 \mathrm{Mbp}$ of sequence, using AlignX software at default settings. The genomic structure of these contigs was elucidated and annotated in the Vector map software (VectorNTI 11). Primers (Table 2) were designed to amplify $\sim 1.2 \mathrm{kbp}$ fragments of BraA.CAX1.a beginning upstream from the deduced transcriptional start site to a region within the gene using Primer 3 (Version 0.4.0) [40] with the parameters "Max Self Complementarity" and "Max 3' Self Complementarity" adjusted to 2, to avoid hairpin loops and potential dimerisation. Primers to amplify the BraA. MET1.a gene (Table 2) from B. rapa $\mathrm{R}-\mathrm{o}-18$ were designed based on the sequence described by Fujimoto et al. [[31], Genbank:AB251937].

\section{Amplification of locus specific sequences from B. rapa $\mathbf{R}$ - o-18}

DNA was extracted from leaves of wild-type B. rapa Ro-18 using the GenElute ${ }^{\circledR}$ Plant Genomic DNA Miniprep kit (Sigma-Aldrich, Gillingham, UK) according to the manufacturer's instructions and subjected to PCR amplification using primers (Table 2) designed to Brassica contig sequence. Amplified fragments were ligated in plasmid $\mathrm{pCR} 8^{\circledR} / \mathrm{GW} / \mathrm{TOPO}^{\circledR}$ (Invitrogen, Paisley, $\mathrm{UK})$ and subsequently sequenced.

\section{Plant genomic DNA extraction}

Genomic DNA was extracted from the BraA.met1.a plants using the DNeasy Plant Min kit (Qiagen, Crawley, UK) following the manufacturer's instructions or using a rapid salt-extraction method [41]. For the BraA.cax1.a plants, a high throughput extraction method was developed based on a method developed by Dr. M. Poole (pers. comm.). A $0.25 \mathrm{~cm}^{2}$ diameter leaf disc from a developing or mid-expansion leaf from each plant was placed in a 96-well plate (Qiagen Collection Microtubes, 
Qiagen, Crawley, UK), with a single $3 \mathrm{~mm}$ stainless steel ball and a $600 \mu$ l aliquot of DNA extraction buffer (200 mM Tris-HCL pH 7.5, $250 \mathrm{mM} \mathrm{NaCl}, 25$ mM EDTA and $0.5 \% \mathrm{w} / \mathrm{v}$ SDS) added to each well. Suspensions were shaken for $3 \mathrm{~min}$ in a ball mill (8000 Mixer Mill, Glen Creston, Stanmore, UK) until the majority of tissue was disrupted. Plates were subsequently centrifuged in a plate centrifuge (Centrifuge 5804, Eppendorf UK, Cambridge, UK) at 5,600 g for $20 \mathrm{~min}$. After centrifugation $300 \mu \mathrm{l}$ of the supernatant was transferred to a fresh plate (Thermofisher storage plate with rubber sealing mat, Fisher, Loughborough, UK), containing $300 \mu \mathrm{l}$ of $100 \%$ isopropanol, mixed and incubated for $3 \mathrm{~min}$ at room temperature. Plates were then centrifuged at 5600 g for 20 min before discarding the supernatant. A 100 $\mu \mathrm{l}$ aliquot of $70 \%(\mathrm{v} / \mathrm{v})$ ethanol was added and mixed by shaking vigorously for $5 \mathrm{~min}$, centrifuged at 5,600 g for $20 \mathrm{~min}$. The supernatant was discarded and dried in a vacuum manifold for $10 \mathrm{~min}$. DNA was resuspended in $20 \mu \mathrm{l}$ sterile $\mathrm{H}_{2} \mathrm{O}$. The DNA concentration was not quantified and standardized due to the number of samples extracted simultaneously.

\section{High Resolution Melt (HRM) analysis}

Primers were designed for HRM analysis to amplify 100250 bp regions within the BraA.CAX1.a gene and a 399 bp region of BraA.MET1.a, which were originally used to identify mutations by TILLING. Three sets of HRM primer pairs were designed for BraA.CAX1.a and one for BraA.MET1.a (Table 2), using Primer 3 (Version 0.4.0) with the parameters "Max Self Complementarity" and "Max 3' Self Complementarity" adjusted to 2, and a $\mathrm{T}_{\mathrm{m}} \geq 60^{\circ} \mathrm{C}$, to avoid hairpin loops and dimerisations. Primer sequences were examined further by primer thermodynamic software (Vector NTI 11) to confirm that no secondary structures were likely to form. HRM primer amplification efficiencies and specificities, were determined in vitro by PCR amplification of wild-type $B$. rapa $\mathrm{R}$-o-18 DNA in reaction volumes containing $10 \mu \mathrm{l}$ of GoTaq buffer $(5 \times), 5 \mu \mathrm{l}$ of $\mathrm{MgCl}_{2}(25 \mathrm{mM}), 1 \mu \mathrm{l}$ of dNTPs $(10 \mathrm{mM}), 5 \mu \mathrm{l}$ of both forward and reverse primers $\left(10 \mathrm{pmol} \mu \mathrm{l}^{-1}\right)$, DNA (10 ng), $0.2 \mu \mathrm{l}$ of Taq polymerase (GoTaq) and sterile de-ionised water (SDW) to a total volume of $50 \mu \mathrm{l}$. PCR conditions were $95^{\circ} \mathrm{C}$ for 5 min and 30 cycles of $95^{\circ} \mathrm{C}$ for $10 \mathrm{sec}, 55^{\circ} \mathrm{C}$ for $10 \mathrm{sec}$ and $72^{\circ} \mathrm{C}$ for $30 \mathrm{sec}$.

\section{Nested PCR approaches to amplify locus specific fragments for HRM analysis}

The nested PCR approach was used for the BraA.CAX1. $a$ lines. DNA extracted from TILLING lines were amplified with TILLING primers using Phusion ${ }^{\mathrm{TM}}$ high fidelity DNA polymerase (New England Biolabs, Hitchin, UK) to ensure sequence integrity of amplified sequences.
Reaction volumes comprised of $4 \mu \mathrm{l}$ of Phusion HF $(5 \times)$, $0.4 \mu \mathrm{l}$ of dNTPs $(10 \mathrm{mM}), 1.4 \mu \mathrm{l}$ of forward and reverse BraA.CAX1.a TILLING primers $\left(10 \mathrm{pmol}^{-1} \mathrm{l}^{-1}\right), 1 \mu \mathrm{l}$ DNA, $0.6 \mu$ l of DMSO, $0.2 \mu \mathrm{l}$ of Phusion DNA polymerase and SDW to a total volume of $20 \mu \mathrm{l}$. PCR conditions involved an initial denaturation at $98^{\circ} \mathrm{C}(30 \mathrm{sec})$ followed by 30 cycles of denaturation at $98^{\circ} \mathrm{C}(5-10 \mathrm{sec})$, annealing at $58^{\circ} \mathrm{C}(15 \mathrm{sec})$ and extension at $72^{\circ} \mathrm{C}(30 \mathrm{sec})$.

\section{HRM reactions}

HRM were performed using Type-it ${ }^{\circledR}$ HRM $^{\text {TM }}$ PCR kit (Qiagen, Crawley, UK) following manufacturer's instructions; $1 \mu \mathrm{l}$ of the initial nested PCR reaction for the BraA.cax1.a lines and $1 \mu \mathrm{l}$ of genomic DNA for the BraA.met1.a lines was added as template to the HRM PCR reaction mix comprising $5 \mu$ of $2 \times$ HRM PCR Master Mix (including EvaGreen fluorescent dye), 1.75 $\mu \mathrm{l}$ of forward and reverse HRM primers $\left(10 \mathrm{pmol} \mu \mathrm{l}^{-1}\right)$ and SDW to $10 \mu \mathrm{l}$. Using an Eppendorf 96-well MasterCycler 5331, reaction volumes were subjected to $95^{\circ} \mathrm{C}$ ( 5 $\mathrm{min})$, followed by 30 cycles of $95^{\circ} \mathrm{C}(10 \mathrm{sec}), 55^{\circ} \mathrm{C}$ annealing (10 sec) and $72^{\circ} \mathrm{C}$ extension (30 sec). Included within each 96-well analysis plate were samples in triplicate, also triplicate wild-type DNA samples and two sets of negative controls, one without DNA added and one without HRM primer added.

\section{LightscannerTM analysis of HRM products}

PCR plates containing HRM amplicons were placed into a LightscannerTM (Idaho Technology, Salt Lake City, USA) and the temperature raised to $60^{\circ} \mathrm{C}$ for 5 mins to ensure all samples were equilibrated. The melt temperature range was set at $63.3^{\circ} \mathrm{C}-95.4^{\circ} \mathrm{C}$ with a ramp setting at $0.1^{\circ} \mathrm{C}$ and a second hold at each step. Exposure was set at "Auto", background correction to exponential, curve shift to 0.020 , standards to 'Auto Group', and sensitivity at normal +2.8. HRM analysis was then performed on the dissociation of double-stranded DNA PCR products, which had been saturated with the low PCR-toxic dye, EvaGreen from the initial HRM PCR. The LightScanner ${ }^{\mathrm{TM}}$ Data Analysis software (Version 2.0, Idaho Technology) was used to analyse the data and produce normalised disassociation curves and difference plots.

\footnotetext{
Acknowledgements

Funding for this work was provided by BBSRC (grant reference BB/G013969/ 1) to $N G, J H, M R B$ and GJK and (BB/F009721/1) to GJK, SK and AS.

Author details

${ }^{1}$ School of Biosciences, University of Nottingham, Sutton Bonington Campus, Loughborough LE12 5RD, UK. 'Rothamsted Research, Harpenden AL5 2JQ, UK. ${ }^{3}$ Department of Crop Genetics, John Innes Centre, Norwich, NR4 7UH, UK. ${ }^{4}$ Southern Cross Plant Science, Southern Cross University, PO Box 157Lismore NSW 2480, Australia. ${ }^{5}$ The James Hutton Institute, Invergowrie, Dundee, DD2 5DA, UK.
} 


\section{Authors' contributions}

SÓL developed and performed the BraA-cax1.a analysis and took the co-lead role in writing the manuscript. SA developed and performed the BraA-met1. $a$ analysis. NG performed the BraA-cax1.a analysis and took the co-lead role in writing the manuscript. KA and JJR performed the BraA-cax1.a analysis. AS and SK developed the HRM analysis. JPH, LØ, GJK, PJW and MRB conceived and participated in development and coordination of the project. All authors contributed to the editing of the manuscript. All authors have read and approved the final manuscript.

\section{Competing interests}

The authors declare that they have no competing interests.

Received: 6 September 2011 Accepted: 8 December 2011

Published: 8 December 2011

\section{References}

1. McCallum CM, Comai L, Greene EA, Heinkoff S: Targeting Induced Lesions IN Genomes (TILLING) for plant functional genomics. Plant Physiology 2000, 123:439-442

2. Till BJ, Cooper J, Colowit P, Greene EA, Henikoff S, Comai L: Discovery of chemically induced mutations in rice by TILLING. BMC Plant Biology 2007, 7:19.

3. Stephenson P, Baker D, Girin T, Perez A, Amoah S, King GJ, Østergaard L: A rich TILLING resource for studying gene function in Brassica rapa. BMC Plant Biology 2010, 10:62

4. Till BJ, Reynolds SH, Greene EA, Codomo CA, Enns LC, Johnson JE, Burtner C, Odden AR, Young K, Taylor NE, Henikoff JG, Comai L, Henikoff S: Large-scale discovery of induced point mutations with high-throughput TILLING. Genome Research 2003, 13:524-530.

5. Azpiroz R, Feldman KA: T-DNA insertion mutagenesis in Arabidopsis: Going back and forth. Trends in Genetics 1997, 13:152-156.

6. Balcells $L$, Swinburne J, Coupland G: Transposons as tools for the isolation of plant genes. Trends in Biotechnology 1991, 9:31-37.

7. Uauy C, Paraiso F, Colasuonno P, Tran RK, Tsai H, Berardi S, Comai L, Dubcovsky J: A modified TILLING approach to detect induced mutations in tetraploid and haexaploid wheat. BMC Plant Biology 2009, 9:115.

8. Botticella E, Sestili F, Hernandez-Lopez A, Phillips A, Lafiandra D: High Resolution Melting analysis for the detection of EMS induced mutations in wheat Sbella genes. BMC Plant Biology 2011, 11:156

9. Wang N, Wang YJ, Tian F, King GJ, Zhang CY, Long Y, Shi L, Meng JL: A functional genomics resource for Brassica napus: development of an EMS mutagenized population and discovery of FAE1 point mutations by TILLING. New Phytologist 2008, 180:751-765.

10. Perry JA, Wang TL, Welham TJ, Gardner S, Pike JM, Yoshida S, Parniske M: A TILLING reverse genetics tool and a web-accessible collection of mutants of the legume Lotus japonicus. Plant Physiology 2003, 131:866-871.

11. Le Signor C, Savois V, Aubert G, Verdier J, Nicolas M, Pagny G, Moussy F, Sanchez M, Baker D, Clarke J, Thompson R: Optimizing TILLING populations for reverse genetics in Medicago trunculata. Plant Biotechnology Journal 2009, 7:430-441.

12. Knoll JE, Ramos ML, Zeng Y, Holbrook CC, Chow M, Chen S, Maleki S, Bhattacharya A, Ozias-Akins P: TILLING for allergen reduction and improvement of quality traits in peanut (Arachis hypogaea L.). BMC Plant Biology 2011, 11:81.

13. Gady ALF, Hermans FWK, Van de Wal MHBJ, van Loo EN, Visser RGF, Bachem CWB: Implementation of two high through-put techniques in a novel application: detecting point mutations in large EMS mutated plant populations. Plant Methods 2009, 5:13.

14. Vriet C, Welham T, Brachmann A, Pike J, Perry J, Parniske M, Sato S, Tabata S, Smith AM, Wang TL: A suite of Lotus japonicus starch mutants reveals both conserved and novel features of starch metabolism. Plant Physiology 2010, 154:643-655.

15. Gundry CN, Vandersteen JG, Reed GH, Pryor RJ, Chen J, Wittwer CT: Amplicon melting analysis with labeled primers: A closed-tube method for differentiating homozygotes and heterozygotes. Clinical Chemistry 2003, 49:396-406.

16. Garritano S, Gemignani F, Voegele C, Nguyen-Dumont T, Le Calvez-Kelm F, De Silva D, Lesueur F, Landi S, Tavtigian SV: Determining the effectiveness of High Resolution Melting analysis for SNP genotyping and mutation scanning at the TP53 locus. BMC Genetics 2009, 10:5.

17. Martino A, Mancuso T, Rossi AM: Application of high-resolution melting to large-scale, high-throughput SNP genotyping: A comparison with the TaqMan ${ }^{\circledR}$ method. Journal of Biomolecular Screening 2010, 15:623-629.

18. Monis PT, Giglio S, Saint CP: Comparison of SYT09 and SYBR Green I for real-time polymerase chain reaction and investigation of the effect of the dye concentration on amplification and DNA melting curve analysis. Analytical Biochemistry 2005, 340:24-34.

19. Dong C, Vincent K, Sharp P: Simultaneous mutation detection of three homoeologous genes in wheat by High Resolution Melting analysis and Mutation Surveyor ${ }^{\oplus}$. BMC Plant Biology 2009, 9:143.

20. Wittwer $C T$, Reed GH, Gundry CN, Vandersteen JG, Pryor RJ: High-resolution genotyping by amplicon melting analysis using LCGreen. Clinical Chemistry 2003, 49:853-860.

21. Poláková KM, Loptová T, Klamová H, Moravcová J: High-resolution melt curve analysis: Initial screening for mutations in BCR-ABL kinase domain. Leukemia Research 2008, 32:1236-1243.

22. Joly P, Lacan P, Garcia C, Delasaux A, Francina A: Rapid and reliable $\beta$ globin gene cluster haplotyping of sickle cell disease patients by FRET Light Cycler and HRM assays. Clinica Chimica Acta 2011, 412:1257-1261.

23. Arancia S, Sandini S, De Bernardis F, Fortini D: Rapid, simple, and low-cost identification of Candida species using high-resolution melting analysis. Diagnostic Microbiology and Infectious Disease 2011, 69:283-285.

24. Mader E, Ruzicka J, Schmiderer C, Novak J: Quantitative high-resolution melting analysis for detecting adulterations. Analytical Biochemistry 2011, 409:153-155.

25. Ishikawa T, Kamei Y, Otozai S, Kim J, Sato A, Kuwahara Y, Tanaka M, Deguchi T, Inohara H, Tsujimura T, Todo T: High-resolution melting curve analysis for rapid detection of mutations in a Medaka TILLING library. BMC Molecular Biology 2010, 11:70.

26. Rana D, Boogart T, O'Neil CM, Hynes L, Bent E, MacPherson L, Park JY, Lim YP, Bancroft I: Conservation of the microstructure of genome segments in Brassica napus and its diploid relatives. The Plant Journal 2004, 40:725-733.

27. Parkin IAP, Gulden SM, Sharpe AG, Lukens L, Trick M, Osborn TC, Lydiate DJ: Segmental structure of the Brassica napus genome based on comparative analysis with Arabidopsis thaliana. Genetics 2005, 171:765-781

28. Girin T, Stephenson P, Goldsack CM, Kempin SA, Perez A, Pires N, Sparrow PA, Wood TA, Yanofsky MF, Ostergaard L: Brassicaceae INDEHISCENT genes specify valve margin cell fate and repress replum formation. Plant Journal 2010, 63:329-338.

29. Cheng N-H, Pittman JK, Barkla BJ, Shigaki T, Hirschi KD: The Arabidopsis cax1 mutant exhibits impaired ion homeostasis, development, and hormonal responses and reveals interplay among vacuolar transporters. Plant Cell 2003, 15:347-364.

30. Finnegan EJ, Dennis ES: Isolation and identification by sequence homology of a putative cytosine methyltransferase from Arabidopsis thaliana. Nucleic Acids Research 1993, 21:2383-2388.

31. Fujimoto R, Sasaki T, Nishio T: Characterization of DNA methyltransferase genes in Brassica rapa. Genes \& Genetic Systems 2006, 81:235-242.

32. Parsons BL, Heflich RH: Genotypic selection methods for the direct analysis of point mutations. Mutation Research 1997, 387:97-121.

33. Fitzgerald TL, Kazan K, Li Z, Morell MK, Manners JM: A high-throughput method for detection of homeologous gene deletions in hexaploid wheat. BMC Plant Biology 2010, 10:264.

34. RevGenUK. [http://revgenuk.jic.ac.uk].

35. Altschul SF, Gish W, Miller W, Myers EW, Lipman DJ: Basic Local Alignment Search Tool. Journal of Molecular Biology 1990, 215:403-410.

36. GenBank. [http://www.ncbi.nlm.nih.gov/genbank/]

37. BLAST. [http://blast.ncbi.nlm.nih.gov/Blast.cgi].

38. Brassica Genome Gateway. [http://brassica.bbsrc.ac.uk].

39. Chao KM, Pearson WR, Miller W: Aligning two sequences within a specified diagonal band. Computer Applications in the Biosciences 1992, 8:481-487.

40. Rozen S, Skaletsky HJ: Primer3 on the WWW for general users and for biologist programmers. In Bioinformatics Methods and Protocols: Methods in Molecular Biology. Edited by: Krawetz S, Misener S. Humana Press, Totowa, NJ: 2000:365-386. 
41. Aljanabi SM, Martinez I: Universal and rapid salt-extraction of high quality genomic DNA for PCR-based techniques. Nucleic Acids Research 1997, 25:4692-4693.

doi:10.1186/1746-4811-7-43

Cite this article as: Lochlainn et al:: High Resolution Melt (HRM) analysis is an efficient tool to genotype EMS mutants in complex crop genomes. Plant Methods 2011 7:43.

Submit your next manuscript to BioMed Central and take full advantage of:

- Convenient online submission

- Thorough peer review

- No space constraints or color figure charges

- Immediate publication on acceptance

- Inclusion in PubMed, CAS, Scopus and Google Scholar

- Research which is freely available for redistribution

Submit your manuscript at www.biomedcentral.com/submit
() Biomed Central 